Working Paper \#476

Princeton University

Industrial Relations Section

July 2003

http://www.irs.princeton.edu/pubs/working_papers.html

\title{
Decomposing Wage Gaps Between Ethnic Groups: The Case of Israel
}

\section{Gad Levanon}

Yaron Raviv

\begin{abstract}
Past investigations of the income gaps between Jews and non-Jews in Israel treat non-Jews as one group. In this paper we separate the non-Jewish group into three main religious minorities: Muslims, Christians and Druze and focus on the northern part of Israel, where most minorities live. Using the latest Israeli census, we find significant explained and unexplained income gaps in favor of Jews. The unexplained gaps tend to be larger the more educated the individual. Jews have much higher representation in the more lucrative occupations, and earn significantly more in them. In almost every dimension Muslims suffer from the largest income gaps. Druze, on the other hand, enjoy the lowest income gaps across most of the income distribution, due in large part to direct and indirect benefits they reap from serving in the army. Among minorities, Christians are the most educated and most concentrated in the top occupations, which explains why they enjoy the lowest gaps in the highest percentiles of the income distribution.
\end{abstract}

JEL Classification: J15, J7, J31

Keywords: Minorities, Discrimination and Wage Structure

\footnotetext{
${ }^{1}$ Department of Economics, Princeton University, 001 Fisher Hall, Princeton NJ 08544. We would like to thank Orley Ashenfelter, Roland Benabou, Han Hong, Yair Listokin, Thomas Romer, Harvey Rosen, David Skeie and participants of the public finance lunch seminar at Princeton University. Any remaining errors are ours.
} 


\section{$\underline{\text { 1. Introduction }}$}

The 2000 riots among Israeli Arabs focused public attention on the social and economic conditions of Arabs in Israel. Many commentators pointed to the discrimination against the Arabs in many dimensions, including the labor market, as one of the main explanations for these riots. Previous literature and published statistics show large income differences between Jews and Arabs in Israel, which cannot be explained by differences in individual characteristics.

Past investigations of income gaps between Jews and non-Jews in Israel have treated non-Jews as one group. The main contribution of this paper is to analyze separately the income gaps between Jews and the three main religious minorities: Muslims, Christians and Druze. Given the history of the Jewish-Arab conflict and the different characteristics of the various religious groups, we have reason to believe that the Christians and the Druze are less influenced by inter-religion hostility than the Muslims and it would be interesting to see if this fact has any effect on labor market outcomes.

In this paper we are using the 1995 Israeli Census. To the best of our knowledge, the income gaps between Jews and Arabs in Israel were never investigated using this data set; rather, most of the relevant literature focuses on earlier or smaller data sets. The size of this data set allows us to contribute to the discussion in the following respects: First, we have enough observations to separate the different Arab religious groups and to compare them. Second, previous literature pointed to differences in occupations as one of the main explanations for the income gaps between Jews and Arabs in Israel, and such a large sample size allows us to focus on the concentration of each religious group in a specific occupation or industry. 
In general, the literature on this topic is quite narrow. All of the research on this topic finds large wage gaps between Jews and Arabs, but when this income gap is decomposed, the results show that, in large part, it is not explained by differences in individual characteristics. Some authors interpret the unexplained wage gap as discrimination against Arabs. Lewin-Epstain and Semyonov (1994), for instance, find that more than half of the income gap between Jews and Arabs in Israel cannot be explained by differences in characteristics, including occupational status. Haberfeld and Cohen (1998) find the unexplained part to be a quarter of the wage gap. Wolkinson (1999) provides some micro evidence for discrimination. Using a sample of 48 large industrial companies, Wolkinson found that Arabs are limited both in recruitment and in the type of positions they assume within companies.

In addition to differences in wages and income, previous research also documents large differences in the occupational distribution between Jews and Arabs in the Israeli labor force. Lewin Epstein et al (1994), for example, show that Arab workers are overrepresented in blue-color jobs, but under-represented in academic jobs. Similarly, Gharrah and Cohen (2001) find that educated Arabs are much less likely to work in management or academic-technical occupations than educated Jews, but are much more likely to be found in the educational field.

Most Arabs in Israel live in Arab-only communities, which are usually much smaller than Jewish communities. Previous research suggests that this residential segregation has both advantages and drawbacks for the Arab population. On the one hand, residence in non-Jewish communities limits labor opportunities and variety, but on the other hand, such communities do not have to contend with heavy competition for job opportunities since Jews are not looking for employment in Arab sectors (Lewin-Epstein, Semyonov 1994).

This analysis focuses on the northern part of Israel, where most Christians, Druze, and Muslims live. Using a sample of men aged 25-64 who are not new immigrants and 
do not live in a kibbut $z^{2}$, we find significant explained and unexplained income gaps in favor of Jews, which confirms results from previous literature. The unexplained gaps tend to be larger the more educated the individual. In addition, Jews, who have much higher representation in the more lucrative occupations, thus earn significantly more than other population groups in Israel. The main result of this paper is that in almost every dimension Muslims suffer from the largest income gaps. Druze, on the other hand, enjoys the lowest income gaps across most of the income distribution, due in large part to direct and indirect benefits they reap from being the only minority serving in the army. However, among all the minorities, Christians are the most educated and most concentrated in the top occupations, which explains why they enjoy the lowest gaps in the highest percentiles of the income distribution.

This paper is organized as follows: Section Two introduces the primary religious groups in Israel and their statistical characteristics; Section Three describes the data set, the sample being used, and the methodology; Section Four reports the results for the various decompositions performed and the distribution of occupations across religious groups; and Section Five discusses the main results and directions for future research.

\section{The Main Religions in Israel}

The main religious group Israel, the Jews, makes up more than 80 percent of the population. There are three main minorities in Israel: Muslims, Christians and Druze. In addition, a little more than one percent of the population belongs to some other religion, are new immigrants who are not Jews, or did not report their religion. In this analysis, we are focusing on income gaps between the Jews and the three main minorities. While we realize that there are several sub-groups based on ancestry within the Jewish group, in this work we treat all Jews as members of one group ${ }^{3}$.

\footnotetext{
2 "A voluntary collective community, mainly agricultural, in which there is no private wealth and which is responsible for all the needs of its members and their families." Encyclopedia Judaica, 1969

${ }^{3}$ The only exceptions are new immigrants, who are omitted from most of the analysis for reasons that will be explained later.
} 
Muslims are the largest minority population in Israel, comprising more than twothirds of the entire minority population (Table One). Christians make up the second largest group, while Druze form the smallest of the three. Despite their different religions, all three-minority groups speak the same language - Arabic. The Druze are a Middle Eastern minority group that traces its origins back to eleventh-century Cairo, where it began as an Islamic reform movement. Today, most Druze lives in the mountainous regions of Lebanon, Syria, Israel, and Jordan.

In many respects, the Muslims and the Druze are very similar, while the Christians in the region more closely resemble the Jews. Muslim and Druze populations are younger and less educated; they have higher fertility rates, live in smaller communities and have a much smaller rate of female representation in the labor force. Most of the minorities live in the northern part of Israel.

Historically, the relationship between the Jewish and Arab populations in Israel is rife with conflict and tension. Such a climate of hostility on both sides very likely is a factor in labor market outcomes. While we do not know of any research that attempts to measure the different attitudes between the Jewish majority and the Arab minority, we believe that the most hostile relationship exists between the Jews and the Muslims, since a large part of the Israeli-Arab conflict is actually a Jewish-Muslim conflict. The relationship between Jews, Christians and Druze is probably much less hostile. In addition, the Druze serve in the Israeli army in significant numbers, while members of the other two minorities almost never serve.

\section{Data and Estimation}

We are excluding women from this analysis because there are enormous differences in female labor force participation rates across religions. Table One shows that 71 percent of Jewish women aged 25-64 are in the labor force, compared to less than 20 percent among Muslims and Druze. Since the Arab women who decide to work are 
probably very different from the ones who do not, such a disparity likely would create selection biases that would be very difficult to correct.

Among males, we are focusing on those from the ages of 25 to 64 . Younger males are not included because of marked differences in labor force participation among the groups. Beginning when they are 18, Jewish and Druze males usually serve in the army for 3-4 years, and only then do they enter the job market or institutions of higher education. This career path is very different from the typical course taken by most young Muslims and Christians, who do not serve in the army.

The labor force participation rates across religions are quite similar for males aged 25-40. However, the minority participation rates decline sharply in the older age groups, especially among less educated workers. Because the workers who retire from the labor force are probably quite different from the ones who stay, this, again, can create selection biases. As a robustness check we also used samples with workers younger than 45, the results of which do not change the conclusions presented here.

Since most Druze, Christians, and Muslims live in the northern region of Israel (Table One), we have decided to focus on the income gaps across religions in this areat People in different locations are part of different labor markets. The main purpose of this paper is to compare Jews and minorities with the same characteristics. By limiting our sample to the north, we can compare Druze and Christians to Jews who participate in the same labor market, and not to Jews who are part of others. Admittedly, however, there may be drawbacks to focusing only on the north. The Jews who live in the north, for instance, might have some special unobservable characteristics that will bias our conclusions with regard to general statements about income gaps between Jews and minorities. For example, if some of the better Jewish workers who grew up in the north move to the Tel-Aviv area, but this is not the case for other religions, then this geographical selection will bias our results toward smaller gaps. The mean income of the

\footnotetext{
${ }^{4}$ The northern part of Israel roughly includes the city of Hadera and north of it. Tel-Aviv and Jerusalem are not included.
} 
Jews in the north is about 5 percent lower than the mean income for the entire Jewish population, and this gap still exists even after controlling for individual characteristics. A possible implication is that by limiting our analysis to the north we will observe smaller gaps between Jews and the minorities in question. However, this should not significantly limit our ability to compare the different minorities groups, which is the main purpose of our analysis.

About 3.5 percent of the Jews in the sample are kibbutz members. A kibbutz is a small society of people who live together communally according to socialist principles. For many kibbutz members most, if not all, of the compensation received is in the form of goods and services provided by the kibbutz. The result is that most report a very low level of income or no income at all. This data of course does not reflect their true compensation. Therefore, for our purposes here, we have decided to omit kibbutz members from this analysis.

In the beginning of the 1990's a large wave of Jewish immigration, mostly from the Soviet Union, arrived in Israel. By the time of the 1995 census, these new immigrants made up almost 15 percent of the labor force (Table Two). These new immigrants are much more educated than the veteran Jews: More than 62 percent of them have more than 12 years of schooling, compared to only 38 percent among veteran Jews. However, since they are relatively new to Israel, they lack a knowledge of Hebrew, and suffer a disadvantage in other important factors that influence labor market outcomes, their income is much lower than that of veteran Jews. This gap is especially large among the more educated population. Many of the immigrants who had lucrative occupations, particularly as engineers and medical doctors, could not find jobs in their fields and, on average, earn less than one-half the income earned by veteran Jews with the same occupations.

Thus these new immigrants clearly face a very different wage schedule than the veteran Jews. In addition, there was no parallel immigration among the other religious groups in Israel. Since the main purpose of this paper is to compare Jews and minorities 
with the same characteristics, and since there are almost no minorities who are new immigrants, we have decided to omit the new immigrant population of Jews from most of our analysis.

The income measure throughout this analysis is the summation of the net incomes from both employed and self-employed occupations $\mathrm{B}^{\mathrm{B}}$ Employed workers are much more common than self-employed respondents. There are 22 income categories for employed income and 20 categories for self-employed categories. In each category, we are using the value of the average income of a worker in that category for each religious group.

Our main independent variables are age and education. The age variable is divided to five years age groups, and we are using dummy variables for each of these groups. To measure an individual's level of education, we are using two separate variables: years of schooling and the highest diploma received. Years of schooling are divided into seven dummy variables and highest diploma received is divided into ten. In addition, we control for whether the worker is currently a student as, in most cases, being a student significantly reduces one's level of income. Other variables we control for are family status and town size ${ }^{6}$.

\section{Methodology}

The most common technique to decompose wage gaps into explained and unexplained parts is the Oaxaca (1973) decomposition or some variation of the same method. Denote $\mathrm{W}_{\mathrm{j}}$ and $\mathrm{W}_{\mathrm{a}}$ as the wage of Jewish worker and Arab minority respectively. In the absence of discrimination, the Jewish/Arab wage gap reflects productivity differences only. Assuming that the wage schedule for individual $\mathrm{i}$ from group $\mathrm{k}$ follows the wage equation: $\log W_{i k}=B_{k} X_{i k}$ where $\mathrm{X}_{\mathrm{ik}}$ is a vector of individual characteristics of individual $i$ from group $k$ and $B_{k}$ is the wage schedule for that group. Denote $B_{j}, B_{a}$ and

\footnotetext{
${ }^{5}$ The wage report here is monthly wage in Israeli shekels. The exchange rate in the census date was approximately 3.01 shekels per USA dollar.

${ }^{6}$ In later analysis we control for occupation and industry. The description of these variables will be given later.
} 
$\mathrm{B}^{*}$ as the least square coefficients for the Jewish population, the least square coefficients for the Arab population and the nondiscrimanory wage structure respectively. Then we can decompose the difference between the geometric mean of the wage of the Jewish worker and that of the wage of the Arab worker in the following way:

$\overline{\log } W_{j}-\overline{\log } W_{a}=B^{*}\left(\bar{X}_{j}-\bar{X}_{a}\right)+\overline{X_{j}}\left(B_{j}-B^{*}\right)+\overline{X_{a}}\left(B^{*}-B_{a}\right)$

The three elements on the right hand side of the equation represent: productivity differences between the Jewish worker and Arab worker, the "benefit" of being a Jewish worker and the "cost" of being an Arab worker respectively. The last two terms are usually referred to as the market discrimination or the unexplained wage gaps. The problem is how to choose the nondiscriminatory wage schedule, $\mathrm{B}^{*}$. Researchers usually assume that $B^{*}=\Omega \mathrm{B}_{\mathrm{j}}+(\mathrm{I}-\Omega) \mathrm{B}_{\mathrm{a}}$, where $\Omega$ is a weighting matrix and I is the identity matrix.

Until the mid-eighties researchers usually used one of the ethnic groups as a base, which means $\Omega$ was equal to the identity matrix or the 0 matrix. We will follow Cotton (1988) who chooses the weighting matrix $\Omega=P_{j}^{*} I$, where $P_{j}$ is the fraction of the sample made up by the Jewish workers. The motivation for choosing this schedule is the following. If one assumes that: 1) In the absence of discrimination the Jewish worker should receive lower average wage while the Arab worker should receive higher average wage. 2) The nondiscriminatory schedule is a linear combination of the two separates schedules. 3) The nondiscriminatory wage will be close to the majority group. 4) Neither total actual output nor total wage would change in the absence of discrimination, then weighting the Jewish wage structure and the Arab wage structure by the respective proportion in the sample will fulfill those assumptions.

\section{Results}

We will start by comparing the decompositions with new immigrants (Table Three). Our sample includes all men aged 25-64 who received positive income during the 
census month, lived in northern Israel, and were not kibbutz members. We have estimated the income schedule for each group separately and then decomposed the gaps in the mean log income ${ }^{\square}$. The bottom row of Table Three shows the total gap between the mean log income of the Jews and of the three other minorities $\frac{8}{\text {. }}$

We then divide the decomposition into explained and unexplained categories. In each portion we also show the part that is attributed to education and age. The omitted dummies in the age and education variables are for the youngest and the least educated. Thus, the value for education in the explained part measures the size of the gap due to the Jews having more years of schooling, while the value for education in the unexplained part measures the size of the gap due to Jews having larger returns to education.

The most important row in this table is the one measuring the total unexplained gap. This value roughly measures a weighted average of the gap between workers from different religions with the same characteristics. This is a residual value that sums up all the determinants of the gap that are not captured by our model. Some of these possible determinants are: knowledge of Hebrew, preferences for professions, segregation of labor markets and discrimination. Obvious variables missing from our estimation are the occupation and industry of the worker. We will come back to these variables later in this paper.

Since the new immigrants are much poorer than the veteran Jews, omitting them from the sample leads to much larger income gaps for each of the three religions. In fact, in the case of the Druze, the unexplained part is negative when new immigrants are included, which means that on average, a Jewish worker will earn less than a Druze with the same characteristics. Thus, for the aforementioned reasons, we will use only samples that do not include new immigrants for the remainder of this paper.

\footnotetext{
${ }^{7}$ We follow the common specification by using the Log of the income as the dependent variable.

${ }^{8}$ Since we are using the mean of the log income we actually measure the gap in the geometric mean. In most cases it is close to the gap in the arithmetic mean.
} 
The results suggest that the total and unexplained gaps are largest for Muslims. We can see that most of these gaps are due to the fact that the Jews are older and more educated than the minorities. Christians, who are also older and more educated than the other minorities, have the lowest explained gap; the Druze has the lowest unexplained gap. When we omit the new immigrants, the unexplained gap is positive for all the groups.

Since the explained component of the gap is relatively self-explanatory, for the rest of the paper we will focus on the unexplained part. By looking at Table Three, we can see that the returns to age and (especially) education are much larger for Jews. This suggests that the unexplained gap is not constant across age and education groups, and is probably larger for older and more educated workers.

We can see this phenomenon in Figure One. We divided the sample to three educational groups: those with less than 11 years of schooling, those with 11-12 years of schooling, and those with more than 12 years of schooling. Each educational group was then divided into three age groups -- 25-34, 35-49 and 50-64 -- thus creating nine ageeducation groups. For each of these nine groups, we computed the mean income for each religion. This very detailed figure reveals many of the results that will be established more rigorously later. It is obvious that the gaps are the largest among the more educated group. In eight out of the nine groups, Muslims earn the lowest mean income. In the two lower educational groups, Druze earns more than the other minorities. However, in the most educated group the Christians earn much more than the Druze, who in fact earn almost as little as the Muslims.

\section{$\underline{\text { Results For Separate Educational Groups }}$}

Given the different outcomes in the different educational groups, we decided to estimate the income gaps in each group separately. After dividing the sample into the three educational groups -- those with less than 11 years of schooling, those with 11-12 years of schooling, and those with more than 12 years of schooling -- we performed a 
separate decomposition in each group. Admittedly, there is a danger that the separation of these groups would bias our results. The most obvious source of such a bias would be if the educational level were correlated with some unobservable characteristics that influence labor market outcomes. For example, 60 percent of the Muslims in our sample have less than 11 years of schooling, compared to 23 percent among the Jews, which suggests that while it is the norm among Muslims living in Northern Israel to have this level of education, for the Jews it is highly unusual. It is possible that a relatively large percentage of the Jews in this category have learning disabilities, problematic families or other unobservable characteristics that negatively influence both their education level and -- later on -- their labor market success. If we could control for these unobservable characteristics, the gaps in favor of the Jews would probably be higher. This logic also holds for other educational groups; we would expect that in each educational group, the positive income gaps that we find would actually be larger if we could control for these factors.

Figure Two represents the size of the unexplained gap, resulting from the wage gap decomposition described above, for each educational group and religion. For each religion, the gap is largest in the most educated group. In each educational group, the gap is largest in the Muslim population. The Druze enjoys the smallest gap in the two lower educational groups; in fact, in the lowest educational group the Druze actually have a negative gap. In the most educated group, however, the gaps for the Christians and the Druze are very similar.

We decided to focus on the gaps in the most educated group for two reasons. First, the gaps in this group are much larger than in the other groups. The Muslims suffer from an almost 30 percent unexplained gap in this group, compared to less than 10 percent in the least educated group. Second, the outcomes in this group influence the incentive to acquire education. If, for example, Muslims have much lower returns to education than Jews, their incentive to acquire education will probably be lower. 
So far, the dependent variable in our estimations was log income, which suggests that the gap we are decomposing is in the mean of the log income, not the gap in the mean income. By using the log specification, we actually decompose the gap in the geometric mean. In Figure One, and more commonly in general, we refer to the arithmetic mean. The gaps in the arithmetic and geometric means should not be very different if the income distributions are roughly the same. In order to compare the two gaps, we decompose the gaps in the arithmetic means by using a different specification. Instead of using log income as our dependent variable, we just use income. The literature in labor economics tells us that this is probably an inferior specification, but we still use it as a robustness check.

Figure Three illustrates the unexplained gaps for the groups with $12+$ years of schooling for each religion, using specifications both with and without logs. We find that when we use the no-logs specifications, the unexplained gap is smaller for the Muslims and Christians but significantly larger for the Druze. We would not put much emphasis on this discrepancy unless it changed one of our conclusions. When we use logs, the unexplained gaps for the Druze and the Christians are similar. However, when we use the no-logs specifications, the gap for the Druze is much larger than that for the Christians. This result suggests that the income distributions within religions could be significantly different and it would not be enough to look just at the gaps in the means. An investigation of the gaps across the income distribution is necessary.

\section{Quantile Regressions Results}

An appropriate method for measuring gaps across the income distribution is quantile regression. The coefficient in a quantile regression produces an expected value of the $\mathrm{x}$ percentile of incomes given a set of characteristics. An ideal way to proceed would be to estimate the expected value of the $\mathrm{x}$ percentile for each religion separately and then decompose the gaps in the same way it was decomposed previously. A necessary condition for the decomposition in the OLS case was that the predicted income evaluated at the sample mean vector of characteristics is exactly equal to the sample 
mean income. Unfortunately, the estimators for the quantile regression model do not have any comparable property.

In this paper, we have used another approach previously used in relevant literature ${ }^{\text {日 }}$. Instead of estimating a separate quantile regression for each religion, we have included the entire sample, and used dummy variables for each minority. The interpretation of the dummy variables is the predicted gap in the income of the $\mathrm{x}$ percentile between the minority and the Jews controlling for the other individual characteristics. The problem with this approach is that we have restricted the coefficients of the individual characteristics to be the same for each religion. This restriction is probably not so crucial in our case since we have employed this approach using only the $12+$ years of schooling group, which leaves us with relatively homogenous sample.

To create Figure Four, we estimated 19 quantile regressions -- at every fivepercentile point between the $5^{\text {th }}$ and $95^{\text {th }}$ percentile. From each regression, we then took the values of the dummy variables for the three minorities. In order to smooth the curves, we used a three point moving average. For example, the value of the dummy variables in the $20^{\text {th }}$ percentile is the average of the values of the $15^{\text {th }} 20^{\text {th }}$ and $25^{\text {th }}$ percentiles. The figure shows the values of the three smoothed dummy variables for each percentile.

The main result in this figure is the difference in the shapes of the curves. In the cases of the Muslims -- and especially the Christians -- we see a U-shaped curve, but not in the case of the Druze. Towards the highest percentiles, the gap between the Jews and the Muslims or Christians decreases significantly, but in the case of the Druze, it is actually increasing. The Muslims suffer from the largest gap throughout the distribution, while the Druze enjoys the smallest gap through most of the distribution. Towards the highest percentiles, however, it is the Christians who have a much smaller gap.

This result can explain the differences in the outcomes between the logs and nologs specifications. When we use the no-logs specification, the very large values become

\footnotetext{
${ }^{9}$ Koenker and Hallock (2001), for example.
} 
much more important in influencing the OLS results. The curves in Figure Four show that, towards the highest percentiles, the gaps for the Muslims and Christians become smaller and the gap for the Druze becomes larger. This result begs the obvious question: Why are the curves in Figure Four the way they are? We will argue that part of the answer has to do with occupations.

\section{Occupational Distribution}

Perhaps the most important determinant of income is occupation. Of course, occupation can also be influenced by religion. We have decided to break down the investigation of the unexplained gap into two main parts. The first stage, which was performed until now, does not take into account differences in occupation, working under the assumption that part of the reason Jews earn more is because they work in more lucrative occupations. The second approach attempts to ascertain whether Jews earn more than minorities with the same characteristics, including occupations.

Table Four presents the occupational distribution of the $12+$ education group. The occupation variable, which includes more than 80 different occupations, has been grouped into six categories. High-tech occupations mainly include scientists, engineers and other technological occupations that require post-high school education. Sophisticated services mainly include medical doctors, pharmacists, lawyers, accountants, professors and psychologists. Managers are workers in managerial positions. Teachers comprise high school, elementary school and kindergarten teachers. Army and security includes workers who serve in the army or work in some security related occupations. It is important to note, however, that the original data set did not include an army category. Rather, people who served in the army were asked to skip the labor market questions in the census, but still report their income. Therefore, we have defined army workers as those who did not answer the question about their occupation but did report their income. 
The most lucrative occupations in the economy are the high-tech, sophisticated services and managers, which are all grouped together at the bottom of Table Four. Significantly, the occupational distribution varies across religions. Minorities are relatively concentrated in teaching for several reasons: First, with more children than adults among the minorities, there is thus a greater need for teachers. Second, the female labor force participation rates among the Jews are much higher and, as such, women take most of the teaching positions. Finally, it is also more difficult for educated minorities to find employment in other lucrative occupations, so they settle for teaching positions.

Jews are relatively more concentrated in high-tech and managerial positions. Surprisingly, though, Muslims and Christians are more concentrated in sophisticated occupations. Druze, however, has by far the lowest concentration in the more lucrative occupations; instead, they are highly concentrated in army and security occupations. The Druze are the only minority that serves in the army and, as Table Four illustrates, a much higher proportion of them, in comparison with the Jews, chooses the army as a career.

In the lucrative occupations, differences in concentration between Christians, Muslims and Druze can partially explain the differences in the shapes of the curves in Figure Four. Towards the highest percentiles, the outcome of the Christians becomes increasingly better than that of the Druze. Hence, the occupational distribution suggests that towards the highest percentiles, more Christians than Druze were working in lucrative occupations.

The results in Figures Two and Four confirm that in the two lower educational groups, as well as throughout most of the income distribution at the top educational group, Druze enjoy the lowest unexplained gap. One of the primary explanations for this result has to do with army service. The Druze are unique in that they are the only minority that serves in the army on a regular basis $\frac{10}{10}$. Even compared to the Jews, Druze

\footnotetext{
${ }^{10}$ There are some army personnel from Bedouin communities, which are Muslim, but they make up a very small percentage of the entire Muslim population.
} 
are much more concentrated in the army; in our sample, 13 percent of the Druze serve in the army, compared to only 3.4 percent among the Jews.

In the 11-12 years of schooling group, Druze are especially concentrated in the army. Indeed, 60 percent of Druze in the army have 11-12 years of schooling, and 21 percent of Druze with this level of education serve in the army. Almost all of those who serve in the army retire before they reach the age of 45, and 63 percent of Druze in the army are under age 35. In general, the wages in the army are considered quite lucrative, especially for younger workers. In fact, by the time a soldier reaches age 25 , he has more experience and seniority than workers his age outside the army.

Figure Five looks at the mean income of Druze in the army aged 25-34 compared to the mean incomes of 25-34 year-old workers of all four religions. In each educational group, Druze in the army earns the highest mean income. The concentration of Druze in such a lucrative occupation directly improves the labor market outcomes of the entire Druze labor force. But there also might be some indirect effects of this phenomenon. Druze concentration in the army increases the labor demand for Druze workers, which likely increases their incomes. Additionally, their service in the army forms a connection between the Druze and the Jewish populations that does not exist in the case of the other minorities. Perhaps this connection improves the Druze's labor market outcomes.

\section{Controlling for Occupations/Industries}

We will now turn to the question of whether Jews earn more than minorities with the same characteristics, including occupations. To determine this, we created 17 dummy variables for occupations and 9 dummy variables for industries and then added them to the original regressions. Our criteria for choosing which occupations and industries to group together were based on proximity, both in terms of the type of occupation/industry and the level of average income. We limited the specification to this number of variables to avoid having no observations for some of the religious groups. The addition of these variables adds significantly to the prediction power of the specifications; however, as a 
control for occupations/industries, it is probably far from perfect. Within each group, there might be some differences in the distribution of the true occupations across religions. For example, there are various types of engineers, but we only know whether a worker is an engineer, not which type. Since the Jews are more concentrated in the more lucrative observable occupations, it is plausible to assume that among engineers they are also more concentrated in the more lucrative types. If this were also true for other groups of occupations/industries, then our results would be biased toward lower gaps; that is, if we could control perfectly for occupations/industries, the unexplained gaps would probably be smaller.

Figure Six shows the unexplained gaps for the three educational groups with and without controlling for occupations/industries. In general, once we control for occupations/industries the gaps are much smaller, reflecting the "occupational advantage" of the Jews. The gaps are still larger for more educated workers, but not nearly as large as in the case of the specifications without occupations/industries. As the figure illustrates, Muslims still suffer from the largest gap in each educational group. The only case where the gap became larger when we controlled for occupations/industries was for Druze with 11-12 years of schooling, which is the education level of most of the Druze serving in the army. As we have seen, the army pays relatively well, and this is the reason it is the only group with an "occupational advantage" over the Jews.

Figure Six shows that, even after controlling for occupations/industries, the gaps are the largest in the 12+ educational group. Thus, the next issue we will undertake is in which occupations the unexplained gap are greatest. We have divided the workers in this group into four categories: people who work in "top jobs" (high-tech, sophisticated services other than doctors, and managers), medical doctors (originally grouped together with veterinarians and pharmacists), teachers and others. There are relatively too few doctors to justify a separate group, but we have chosen to group them separately because the result for this occupation is very unique. In each group of occupations, we performed separate decompositions. 
Figure Seven illustrates the unexplained gaps in the 12+ group for each of the occupations groups. What is significant here is that for all the minorities, the largest gap is in the top jobs group: Even after controlling for individual characteristics and occupations/industries, Muslims and Druze earn over 20 percent less than Jews in these occupations. In this context, doctors constitute a unique group; for both Muslims and Christians, this is the occupation with the lowest gap and, in the case of Christians, it is actually significantly negative. In the end, we have no good explanation for such a result. For Druze doctors, the gap is still quite large, but the result here relies on few observations.

The unexplained gap in the most lucrative occupations (top jobs and doctors) offers the only case where Muslims are not in the worst economic position. Not only do the Druze have the lowest concentration in these occupations, but they also earn the lowest incomes. The gaps in teaching and other occupations are significantly lower than in the top jobs. We find it surprising that any gaps exist at all among teachers, since these are almost entirely government jobs.

\section{$\underline{\text { Segregation }}$}

Most of the minorities in Israel live and work in non-Jewish communities, while Jews work almost entirely in Jewish communities. Previous research shows that this labor market segregation has both advantages and drawbacks for the Arab population. On the one hand, working in non-Jewish communities limits the number and variety of labor opportunities. Moreover, since non-Jewish communities are usually poorer, they likely pay lower wages for a given service. However, on the other hand, such communities do not have to contend with heavy competition for job opportunities since Jews are not looking for employment in Arab sectors, which benefits Arab workers.

Until now, we have ignored the influence of the segregation of labor markets on income gaps, mainly due to insufficient data on the locations of work places. For most workers, we cannot distinguish whether they work in Jewish or non-Jewish communities. 
Even in the case of workers employed in Jewish towns, we do not know whether they are working within the Jewish or non-Jewish community in that town. This issue certainly deserves further treatment, but it is beyond the scope of this data set and analysis.

In this paper, we decided to touch on the topic of segregation only with respect to the "top jobs" because previous results confirm that the largest unexplained gaps are in these occupations. One possible explanation for these gaps is that non-Jewish professionals work mostly within non-Jewish communities, which are poorer on average, and therefore earn lower incomes. The problem is that we cannot discern which professionals work in Jewish communities and which ones work in non-Jewish ones. In a partial attempt to address the issue of segregation in the "top jobs," we have controlled for workers who either worked in the city of Haifa or worked outside of northern Israel. Haifa, which is the third largest city in Israel and by far the largest city in Northern Israel, boasts a mostly Jewish population. We also assume that almost all the workers employed outside northern Israel work in Jewish towns, mostly in the Tel Aviv area.

Across religions, there are large differences in the distribution of employment locations. Almost 50 percent of Jews in "top jobs" work in Haifa, compared to 24 percent of Christians, 22 percent of Druze and only 9 percent of Muslims. By adding the two locations dummies to the "top jobs" specifications from Figure Seven, we found that, for Jews and especially Christians, working in Haifa significantly increases income. This was not the case for Muslims and Druze. In Figure Eight, we can see the unexplained gap in the "top jobs" specification with and without controlling for employment locations. The conclusion here is that once we control for employment location, the unexplained gap becomes significantly smaller. Additionally, the results suggest that the gaps between Jews and Muslims are larger in Haifa than in other locations, but the number of Muslim workers in Haifa is too small for reaching reliable conclusions.

\section{Conclusions}


In order to summarize the main conclusions of this paper, we must separate the results common to all minorities and the results that concentrate on the differences across minorities. As we mentioned before, this analysis focuses on the northern part of Israel, where most of the minorities live. In fact, we believe that focusing on northern Israel actually underestimates the size of income gaps between Jews and minorities.

Jews earn higher average incomes chiefly because they are older and more highly educated, but their incomes are higher even among individuals with the same characteristics. Thus, these unexplained gaps are not uniform across the entire population: the gaps are larger the more educated the individual. Moreover, Jews are much more concentrated in the most lucrative occupations and reap more benefits from working in them. When grouping high-tech workers, sophisticated services (Professionals that are not in the high-tech occupations), and managers into one group, we find that 25 percent of the Jews in our sample work in these "top occupations," compared to 13 percent of Christians and only 5-6 percent of Muslims and Druze. This occupational gap is especially large in the high-tech and managerial occupations. Even when we compare individuals with the same occupations/industries, we find the gaps are largest in these "top occupations." Doctors are an important exception to this rule, however, as minorities are doing extremely well in this field relative to the other "top occupations."

The ability of minorities to enter these more lucrative occupations is quite limited. First, a much smaller percentage of minorities acquire higher education, which is a necessary condition for most of the more lucrative occupations. But even among the educated members of the population, a much lower portion manages to enter the top occupations; instead, they settle for non-academic teaching positions and other less lucrative opportunities. The differences in concentration and income level in the top occupations certainly contribute directly to the income gaps, but they also create different incentives for acquiring higher education, which could offer at least a partial explanation for the gaps in education levels between Jews and non-Jews. 
Most of the minority population is not employed in these top occupations and, for them, the income gaps are much smaller. In fact, the income gaps tend to decrease the less educated the individual, and for the least educated group, the unexplained gap is around zero in some cases. In relation to the rather gloomy results presented so far, this is certainly a more positive scenario: When we compare the more than 90 percent of non-Jews not in the top occupations to Jews with the same individual characteristics, we find much lower gaps.

The main contribution of this paper comes from its separate analysis of each of the three chief minorities in Israel. In many dimensions, these three minorities are all very different. The Christians, for instance, are older and more educated than the Muslims and the Druze, which increases their relative average income. One of the main conclusions of this paper is that Muslims suffer the largest income gaps in almost every benchmark. Druze, on the other hand, enjoy the lowest income gaps across most of the income distribution, which can be explained in part by the direct and indirect benefits they reap from their relatively high rate of service in the Israeli army.

The results of this paper underscore the importance of measuring income gaps across the income distribution and not just between the means. Using quantile regressions, we have found that the results in the upper percentiles are very different from those in the lower ones. Among the upper percentiles of the income distribution, we can see that Christians earn significantly more than the rest of the minorities. Indeed, the Christians in the region are much more successful in acquiring higher education, entering top occupations, and earning relatively high incomes in these occupations. Despite their success across most of the income distribution, Druze have the lowest concentration in top occupations and earn the lowest incomes in these occupations.

We shouldn't be surprised that Muslims suffer from the largest income gaps given that, more than any of the other minorities, they are hindered by their adverse relationship with the Jewish majority. Since the Muslims population is much larger than the other two 
minority groups combined, this gap dominates the overall gap between Jews and nonJews in Israel.

"Unexplained gap" is a residual term that sums up a variety of possible explanations, all of which we could not control for in this paper. Further research on these explanations might allow us to better understand some of the other questions this topic raises: Why do the Muslims suffer from the worst unexplained gap? Why are there so few Druze in top occupations despite their success in other segments of the labor market? And, finally, what is the role of segregation in explaining income gaps?

A very important research topic would be to measure the evolution of these gaps across time, which would allow researchers to disentangle the influence of cohorts from the influence of work experience. The results in this paper suggest that the gaps probably increased since the 1995 census for two reasons. First, 1995 was one of the best years in terms of the Israeli-Arab relationship, which probably reduced tensions and increased labor market integration in Israel. Second, we find that one of the main occupational gaps is in high-tech occupations. Since 1995, high-tech has been perhaps the fastest growing industry in Israel, a trend that involved rapidly increasing wages in some occupations. Almost all of the high-tech companies in Israel are Jewish owned; thus it is unlikely that non-Jews benefited as much as Jews from this trend.

In this paper we focused on the income gaps within the population with $12+$ years of schooling. However, since most non-Jews in Israel are less educated, it would be interesting to explore the gaps among the less educated population with an emphasis on occupational differences. Additionally, there are several sub-groups based on ancestry within the Jewish group. Previous research has shown that Jews from European ancestry earn significantly higher incomes than Jews from Asian or African ancestry. Accordingly, it would be interesting to explore the income gaps between the main minorities and the main Jewish ethnic groups in Israel. Such an analysis would allow us to see how inter-religions gaps are measured compared to inter-ethnic gaps. 


\section{References}

Cotton, Jeremiah, "On the decomposition of wage differentials", Review of Economics and Statistics 70, 1988, 236-243.

Klinov Ruth.” Changes in School Enrollment Patterns in Israel: A Comparison Between Two Disadvantage Groups” Economics of Education Review, vol.15, pp 289-301, 1996.

Koenker Roger, Hallock Kevin. “Quantile Regression” Journal of Economic Perspectives, Fall, 15:4, 2001, pages 143-156.

Levin-Epstein Noah, Semyonov, Moshe. "Sheltered labor market, public sector employment, and socioeconomic returns to education of Arabs in Israel." American Journal of Sociology, Volume 100, Issue 3(Nov., 1994), 622-651.

Lewin-Epstein, Noah, Semyonov, Moshe. "The Arab Minority in Israel's Economy", Chapter 4, Westview Press, 1993

Newman Shoshana and Silber Jacques G. "Wage Discrimination Across Ethnic Groups:

Evidence From Israel, Economic Inquiry, October 1996,648-661.

Neumark, David, 1988, “Employer's discriminatory behavior and the estimate of wage discrimination", Journal of Human Recourses 23,279-295.

Oaxaca, Ronald L. "Male-Female Wage Differentials in Urban Labor Markets," International Economic Review, 14, (1973), pp. 693-709

Oaxaca, Ronald L., Ransom, Michael R. "On discrimination and the decomposition of wage differentials", Journal of Econometrics, Volume 61, (1994), pp.5-21

Reamers, Cordelia, "Labor market discrimination against Hispanic and black men”, Review of Economics and Statistics 65, 1983, 570-579. 
Semyonov, Moshe. "Bi-Ethnic labor Markets, Mono-Ethnic Labor Markets, and Socioeconomic Inequality," American Sociological Review, Volume 53, Issue 2 (Apr., 1988) 256-266.

Semyonov, Moshe, Cohen, Yinon. "Ethnic discrimination and the income of majority-group workers," American Sociological Review, volume 55, issue 1(Feb., 1990), 107-114.

Yitchak Haberfeld and Yinon Cohen.” Earning Of Native-Born Jewish And Arab Men In Israel, 1987-1993”, Research in Social Stratification and Mobility, Volume 16, pages 69-88.

W. Wolkinson, Benjamin. "ARAB EMPLOYMENT IN ISRAEL, The Quest for Equal Employment Opportunity”, Contribution in Labor Studies, Number 53, 1999. 


\section{Table 1 \\ Summery statistics}

\begin{tabular}{|c|c|c|c|c|c|}
\hline & Jewish & Muslim & Christian & Druze & Others \\
\hline \multicolumn{6}{|l|}{ Schooling: } \\
\hline 10 or less & $22.80 \%$ & $58.87 \%$ & $40.73 \%$ & $43.98 \%$ & $21.07 \%$ \\
\hline $11-12$ & $35.84 \%$ & $24.73 \%$ & $29.07 \%$ & $36.62 \%$ & $23.13 \%$ \\
\hline Above 12 & $41.36 \%$ & $16.40 \%$ & $30.20 \%$ & $19.39 \%$ & $55.80 \%$ \\
\hline Wage & $\begin{array}{l}7238 \\
(8536)\end{array}$ & $\begin{array}{l}4710 \\
(6455)\end{array}$ & $\begin{array}{l}5752 \\
(7022)\end{array}$ & $\begin{array}{l}5727 \\
(12630)\end{array}$ & $\begin{array}{l}3516 \\
(3062)\end{array}$ \\
\hline Age & $\begin{array}{l}41.56 \\
(10.22)\end{array}$ & $\begin{array}{l}36.57 \\
(8.98)\end{array}$ & $\begin{array}{l}39.58 \\
(9.98)\end{array}$ & $\begin{array}{l}36.78 \\
(8.71)\end{array}$ & $\begin{array}{l}38.09 \\
(9.28)\end{array}$ \\
\hline Child & $\begin{array}{l}2.6 \\
(1.79)\end{array}$ & $\begin{array}{l}4.36 \\
(2.88)\end{array}$ & $\begin{array}{l}2.91 \\
(2.18)\end{array}$ & $\begin{array}{l}4.15 \\
(2.70)\end{array}$ & $\begin{array}{l}1.51 \\
(1.08)\end{array}$ \\
\hline \multicolumn{6}{|l|}{ Town size: } \\
\hline Above $100 \mathrm{k}$ & $48.15 \%$ & $22.74 \%$ & $27.37 \%$ & $0.77 \%$ & $53.88 \%$ \\
\hline $50 \mathrm{k}-100 \mathrm{k}$ & $12.72 \%$ & $6.42 \%$ & $20.28 \%$ & $0.19 \%$ & $9.92 \%$ \\
\hline $20 \mathrm{k}-50 \mathrm{k}$ & $19.25 \%$ & $12.66 \%$ & $12.97 \%$ & $4.81 \%$ & $21.38 \%$ \\
\hline Bellow 20k & $19.88 \%$ & $58.19 \%$ & $39.39 \%$ & $94.23 \%$ & $14.82 \%$ \\
\hline Female LFP & $71.43 \%$ & $17.07 \%$ & $44.86 \%$ & $19.62 \%$ & $71.62 \%$ \\
\hline Male LFP & $87.45 \%$ & $80.13 \%$ & $84.72 \%$ & $83.86 \%$ & $86.25 \%$ \\
\hline Observations & 118278 & 14354 & 3467 & 2078 & 1742 \\
\hline $\begin{array}{l}\text { Percent } \\
\text { North District: }\end{array}$ & $84.53 \%$ & $10.26 \%$ & $2.48 \%$ & $1.49 \%$ & $1.25 \%$ \\
\hline$\overline{\text { Wage }}$ & 6740 & 4714 & 5815 & 5741 & 3302 \\
\hline Observations & 29405 & 11073 & 2995 & 2075 & 544 \\
\hline $\begin{array}{l}\text { Percent Living } \\
\text { in the North }\end{array}$ & $24.86 \%$ & $77.14 \%$ & $86.38 \%$ & $99.85 \%$ & $31.22 \%$ \\
\hline
\end{tabular}

The sample includes male aged 25-64 belong to the labor force who lived outside Jerusalem and reported some income. The labor force participation for female and male include all individual aged 25-64. The labor force participation for male includes army personal. Standard errors in parenthesis. 


\section{Table 2}

\section{Comparison Between Veteran Jews and New Immigrants}

\begin{tabular}{ccc}
\hline & Veterans & New immigrants \\
\hline $\begin{array}{l}\text { Percent Of Jewish } \\
\text { Population in } \\
\text { Northern Israel }\end{array}$ & 84.56 & 15.44 \\
\hline Mean wage & 7336 & \\
Schooling & & 3591 \\
10 or less & $22.81 \%$ & $20.01 \%$ \\
$11-12$ & $39.17 \%$ & $17.58 \%$ \\
Above12 & $38.02 \%$ & $62.41 \%$ \\
Wage & & \\
10 or less & 5145 & 2700 \\
$11-12$ & 6343 & 3064 \\
Above 12 & 9674 & 4024 \\
\hline
\end{tabular}

The sample includes Jewish males aged 25-64 that belong to the labor force lived in northern Israel and reported some income.

Table 3

Wage Differences Decomposition North District

\begin{tabular}{llllllll}
\hline & \multicolumn{3}{c}{ With New Immigrants } & & \multicolumn{2}{c}{ Without New Immigrants } \\
\cline { 7 - 8 } & Muslims & $\underline{\text { Christians }}$ & Druze & & Muslims & Christians & Druze \\
\hline Total & $\mathbf{2 2 . 3 5 \%}$ & $\mathbf{1 1 . 7 6 \%}$ & $\mathbf{1 8 . 2 9} \%$ & $\mathbf{2 3 . 9 2 \%}$ & $\mathbf{1 2 . 9 0 \%}$ & $\mathbf{2 1 . 3 9 \%}$ \\
$\begin{array}{l}\text { Explained } \\
\text { Education }\end{array}$ & $16.63 \%$ & $8.54 \%$ & $12.25 \%$ & $18.01 \%$ & $9.36 \%$ & $13.78 \%$ \\
Age & $5.53 \%$ & $2.74 \%$ & $5.33 \%$ & $6.03 \%$ & $2.98 \%$ & $5.98 \%$ \\
\hline
\end{tabular}




\begin{tabular}{lllllll}
\hline $\begin{array}{l}\text { Total } \\
\text { Unexplained }\end{array}$ & $\mathbf{6 . 2 7 \%}$ & $\mathbf{1 . 8 6 \%}$ & $\mathbf{- 4 . 9 3 \%}$ & $\mathbf{1 3 . 5 3 \%}$ & $\mathbf{7 . 7 4 \%}$ & $\mathbf{0 . 8 1 \%}$ \\
Education & $9.18 \%$ & $6.64 \%$ & $0.85 \%$ & $13.60 \%$ & $10.22 \%$ & $5.12 \%$ \\
Age & $6.78 \%$ & $3.00 \%$ & $-0.03 \%$ & $8.58 \%$ & $5.40 \%$ & $1.62 \%$ \\
$\begin{array}{l}\text { Total } \\
\text { Difference }\end{array}$ & $\mathbf{2 8 . 6 3 \%}$ & $\mathbf{1 3 . 6 2 \%}$ & $\mathbf{1 3 . 3 7 \%}$ & $\mathbf{3 7 . 4 6 \%}$ & $\mathbf{2 0 . 6 4}$ & $\mathbf{2 2 . 2 0 \%}$ \\
\hline
\end{tabular}

The sample includes men aged 25-64 who belong to the labor force and earn some money in the census month and were residents of the north district. The base regression for each ethnic group includes dummies for town size, age, education, highest diploma and family status. 
Figure - 1

Mean Income Across Age and Educational groups

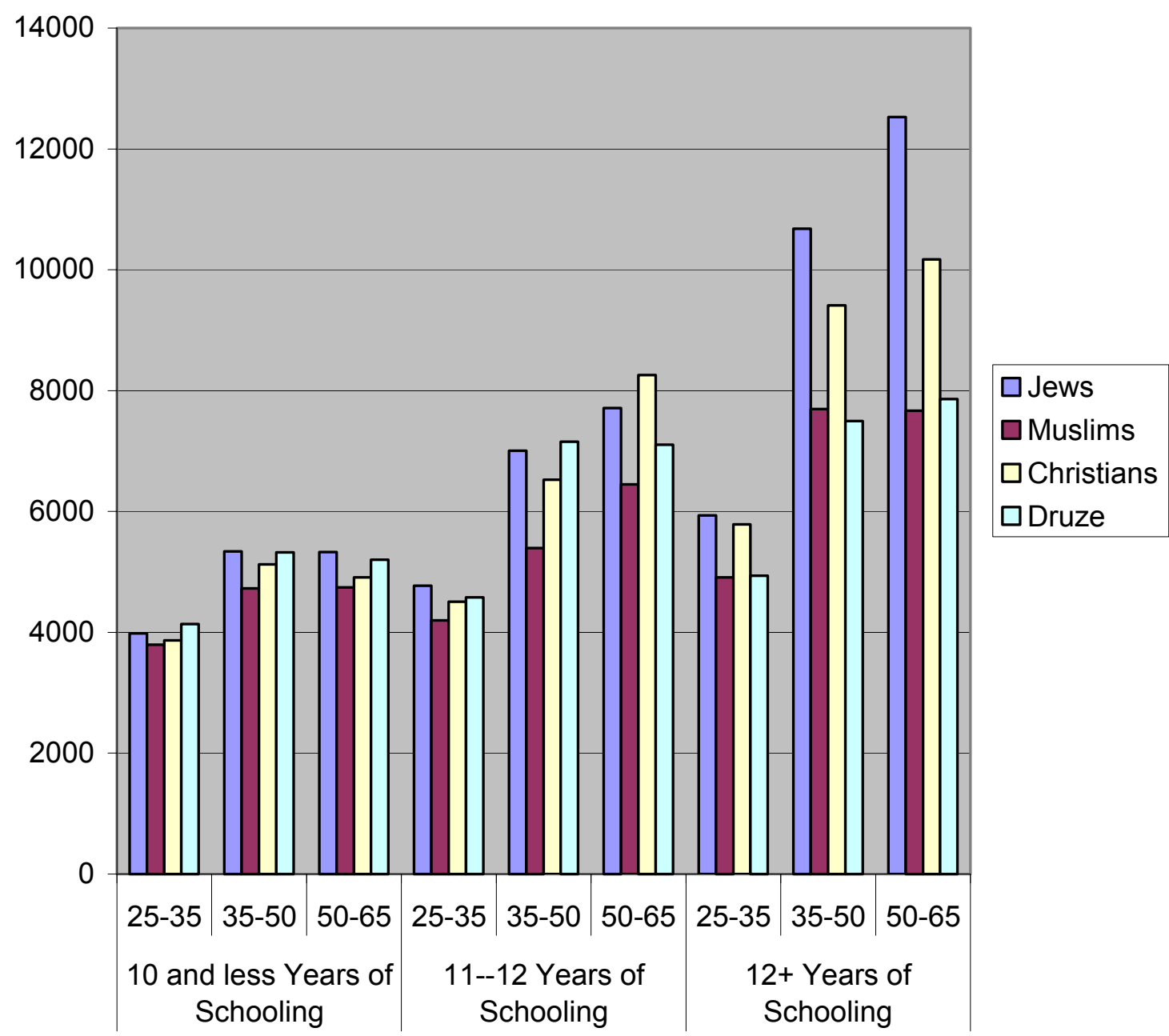


Figure 2 - Unexplained Income Gaps Across

Religions and Education Groups

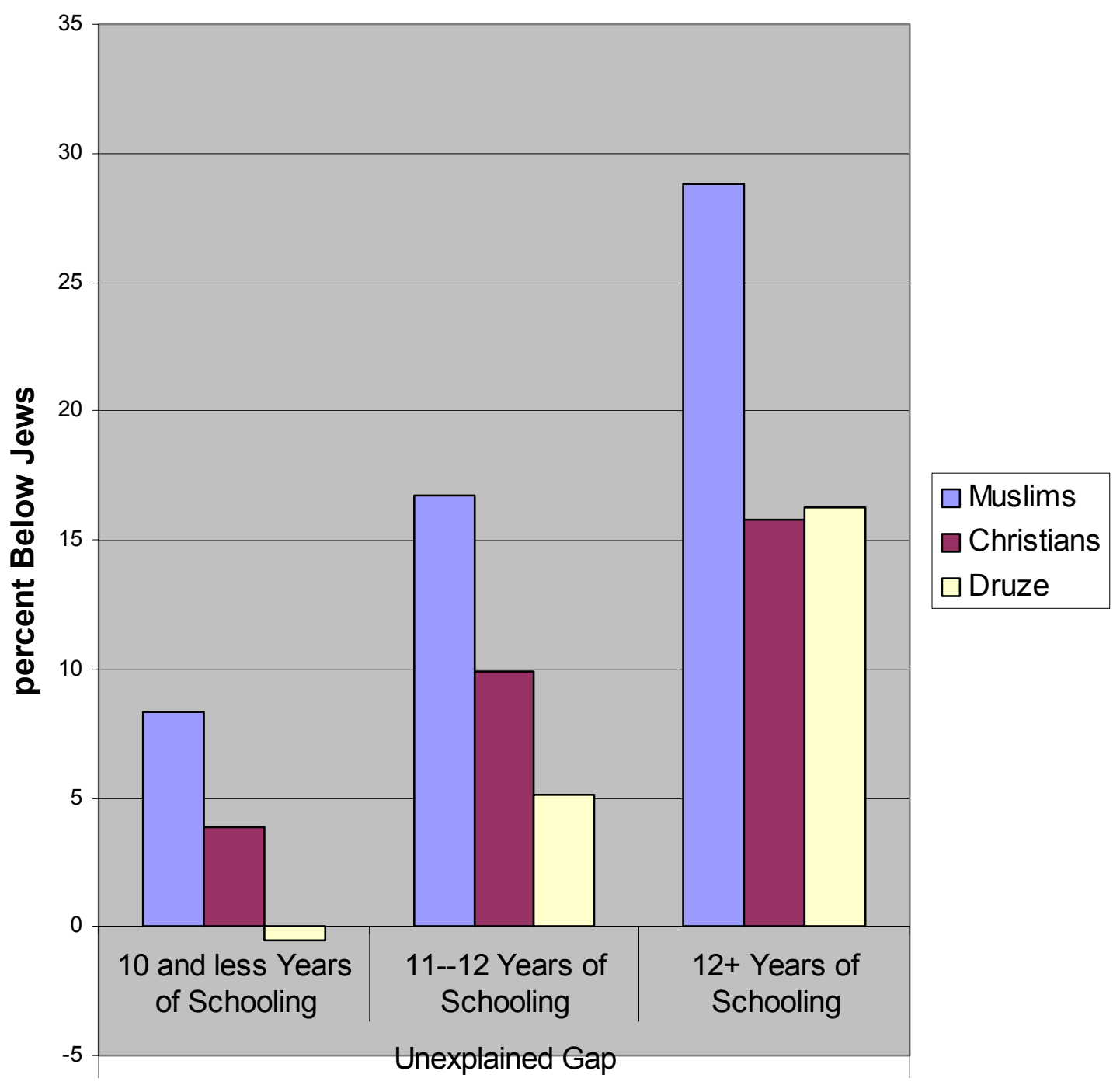


Figure 3 - Unexplained Gaps by Specification (12+ Years of Schooling)

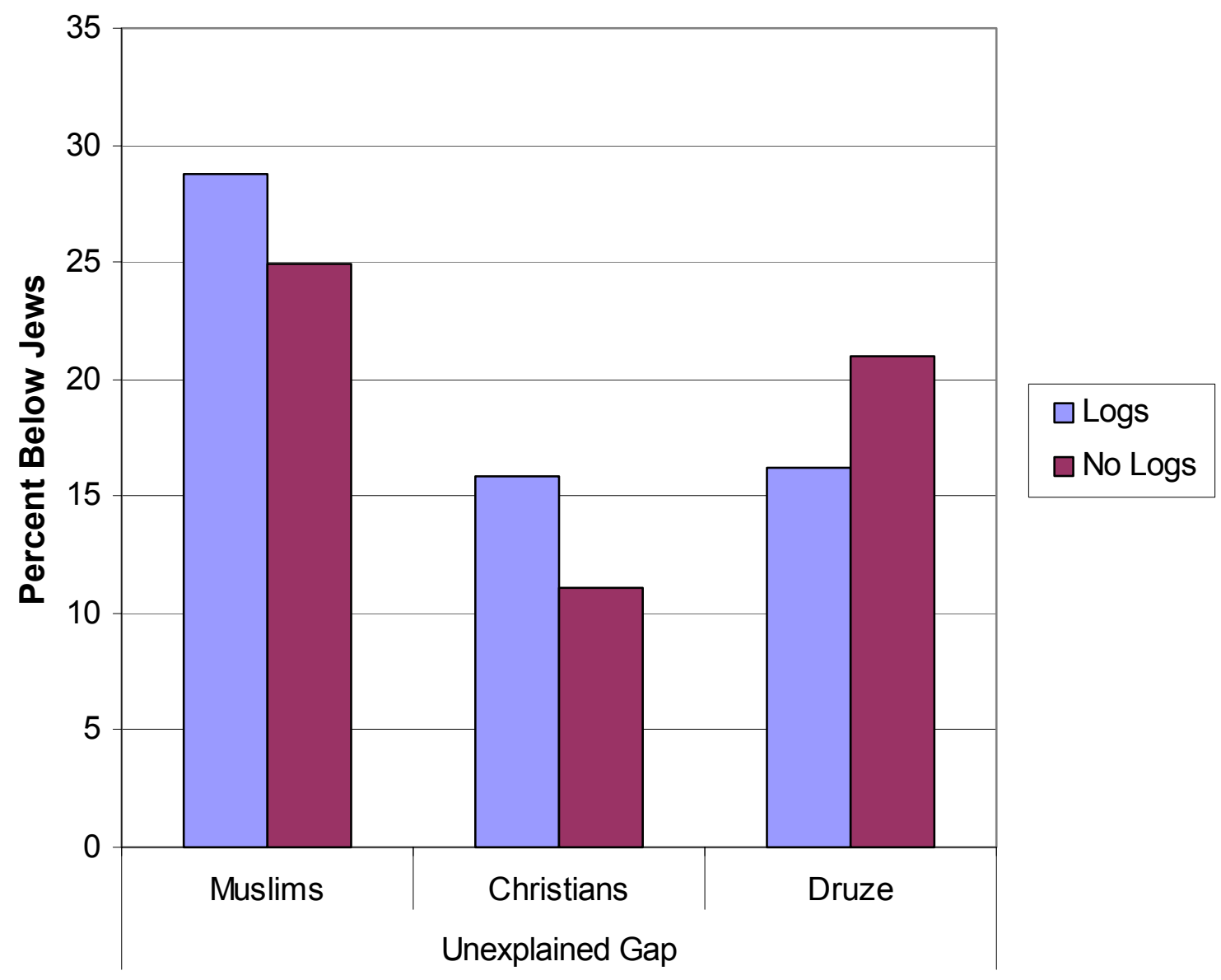


Figure 4

Income Gaps Across Percentiles (12+ Years of Schooling)

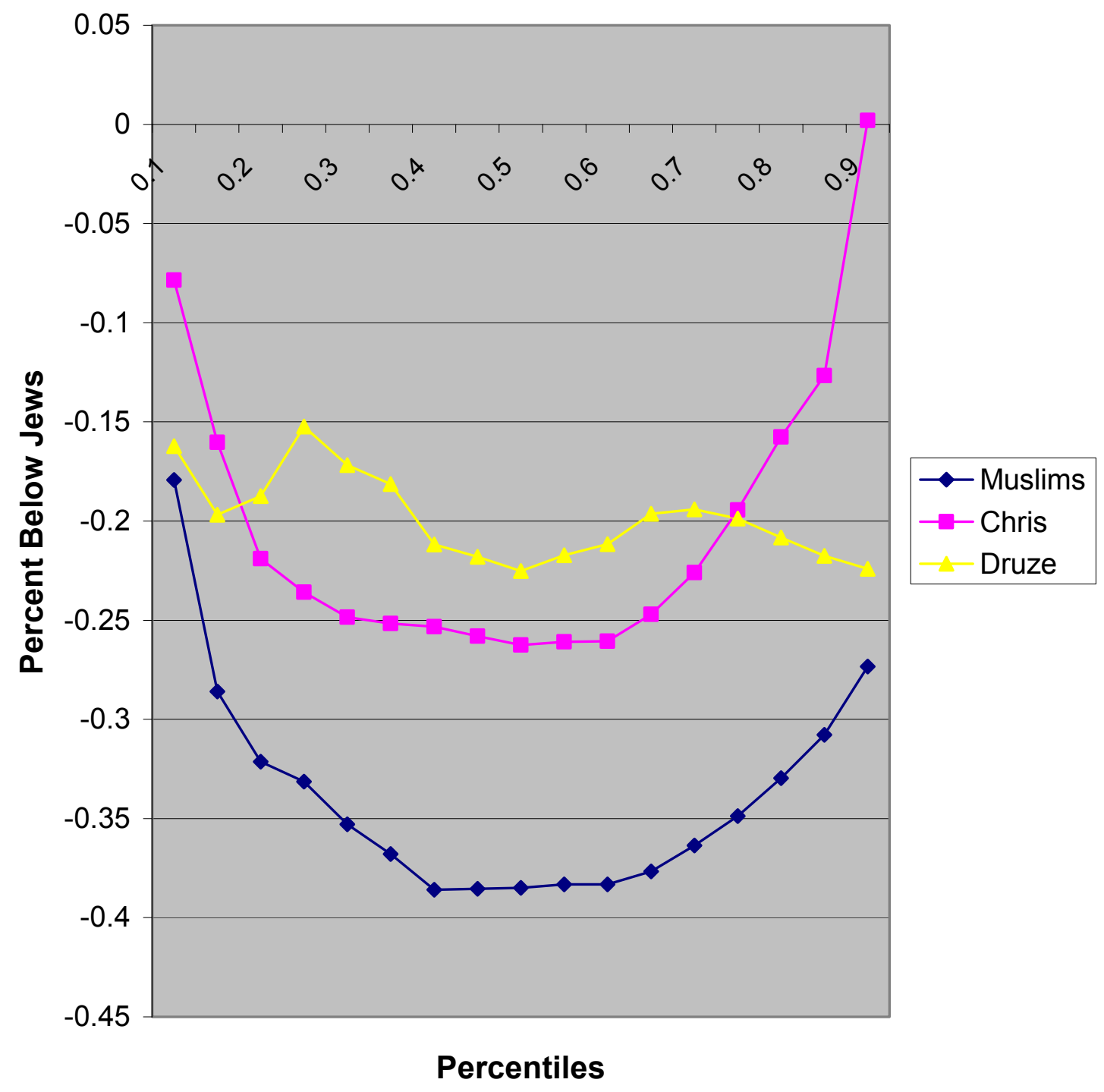


Table 4

Occupational Distribution of the 12+ Education Group

\begin{tabular}{|l|c|c|c|c|}
\hline & Jewish & Muslim & Christians & Druze \\
\hline & $23.95 \%$ & $6.12 \%$ & $12.68 \%$ & $4.99 \%$ \\
\hline Sophisticated services & $10.97 \%$ & $14.26 \%$ & $17.63 \%$ & $5.74 \%$ \\
\hline Managers & $14.35 \%$ & $4.10 \%$ & $5.68 \%$ & $4.74 \%$ \\
\hline & $6.83 \%$ & $32.23 \%$ & $22.10 \%$ & $27.93 \%$ \\
\hline Teachers & & & & \\
\hline Army and Security & $5.72 \%$ & $0.51 \%$ & $0.36 \%$ & $17.71 \%$ \\
\hline & $38.18 \%$ & $42.78 \%$ & $41.55 \%$ & $38.90 \%$ \\
\hline $\begin{array}{l}\text { Other } \\
\text { Hi-Tech, Managers, } \\
\text { Sophisticated Services }\end{array}$ & $49.27 \%$ & $24.48 \%$ & $35.99 \%$ & $15.46 \%$ \\
\hline
\end{tabular}


Figure 5

The Income Of Druze in the Army

Age 25--35

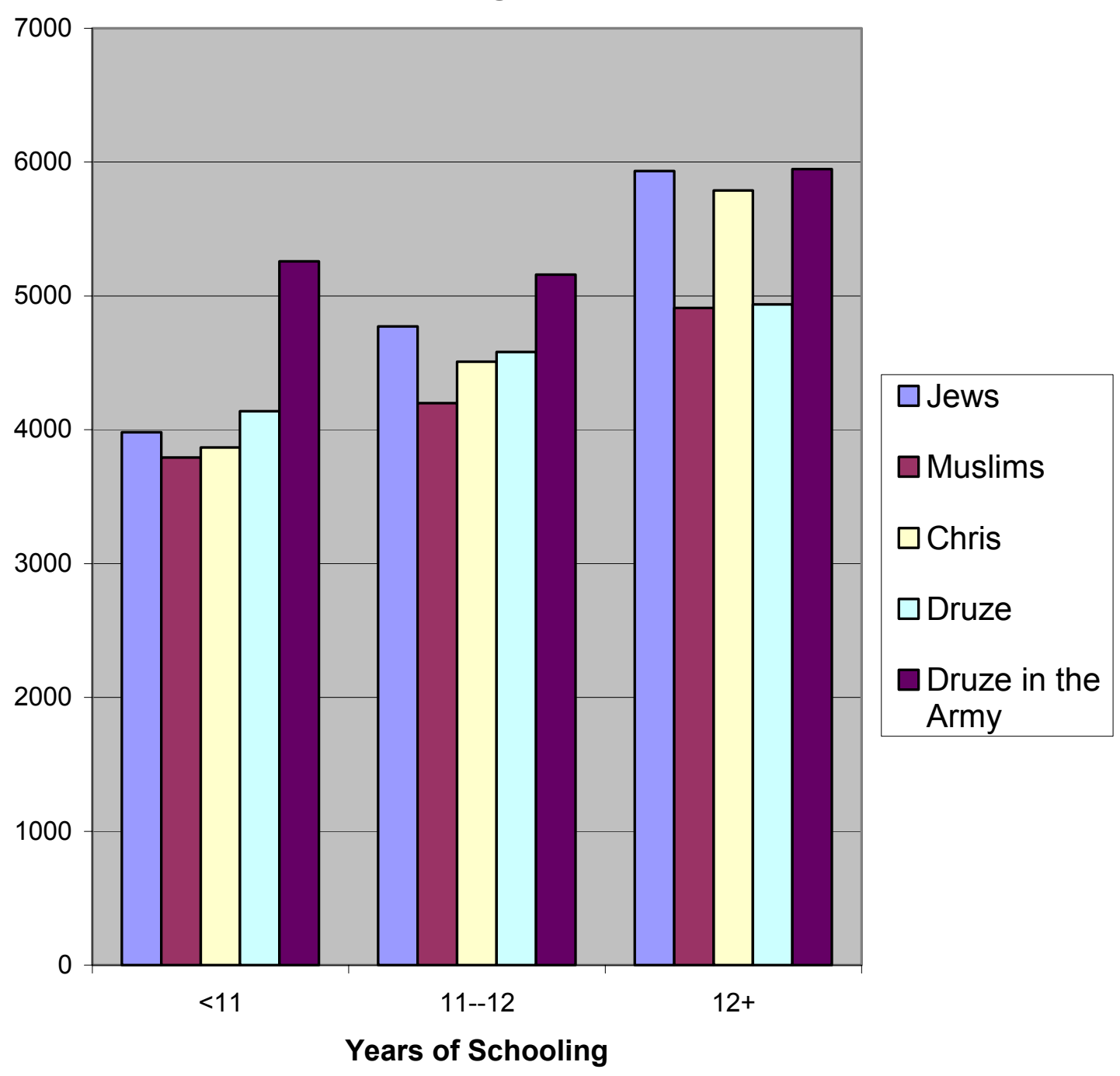


Figure 6

Unexplained Gaps With and Without Occupations

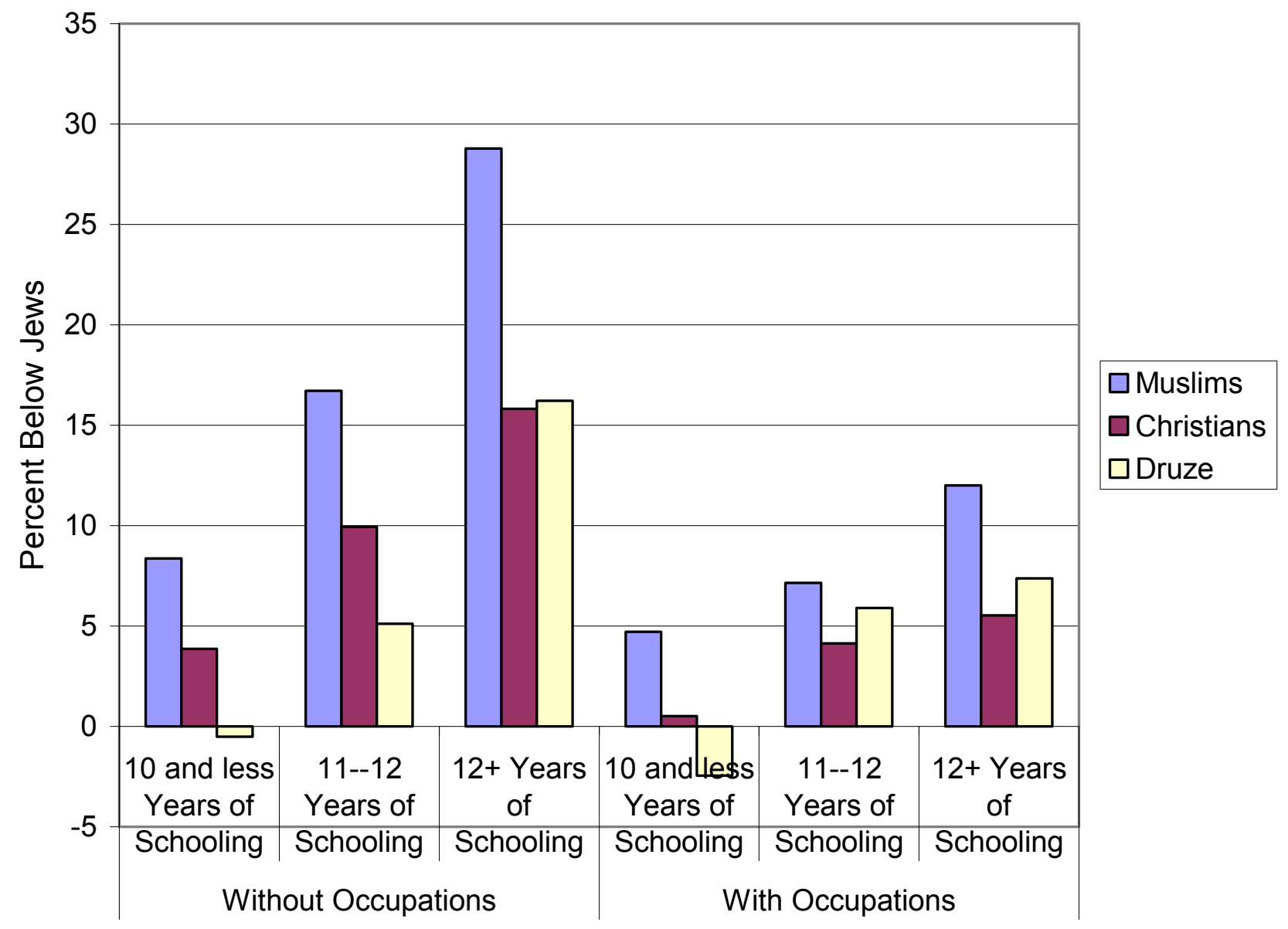


Figure 7

Unexplained Income Gaps Across Occupations

(12+ Years of Schooling)

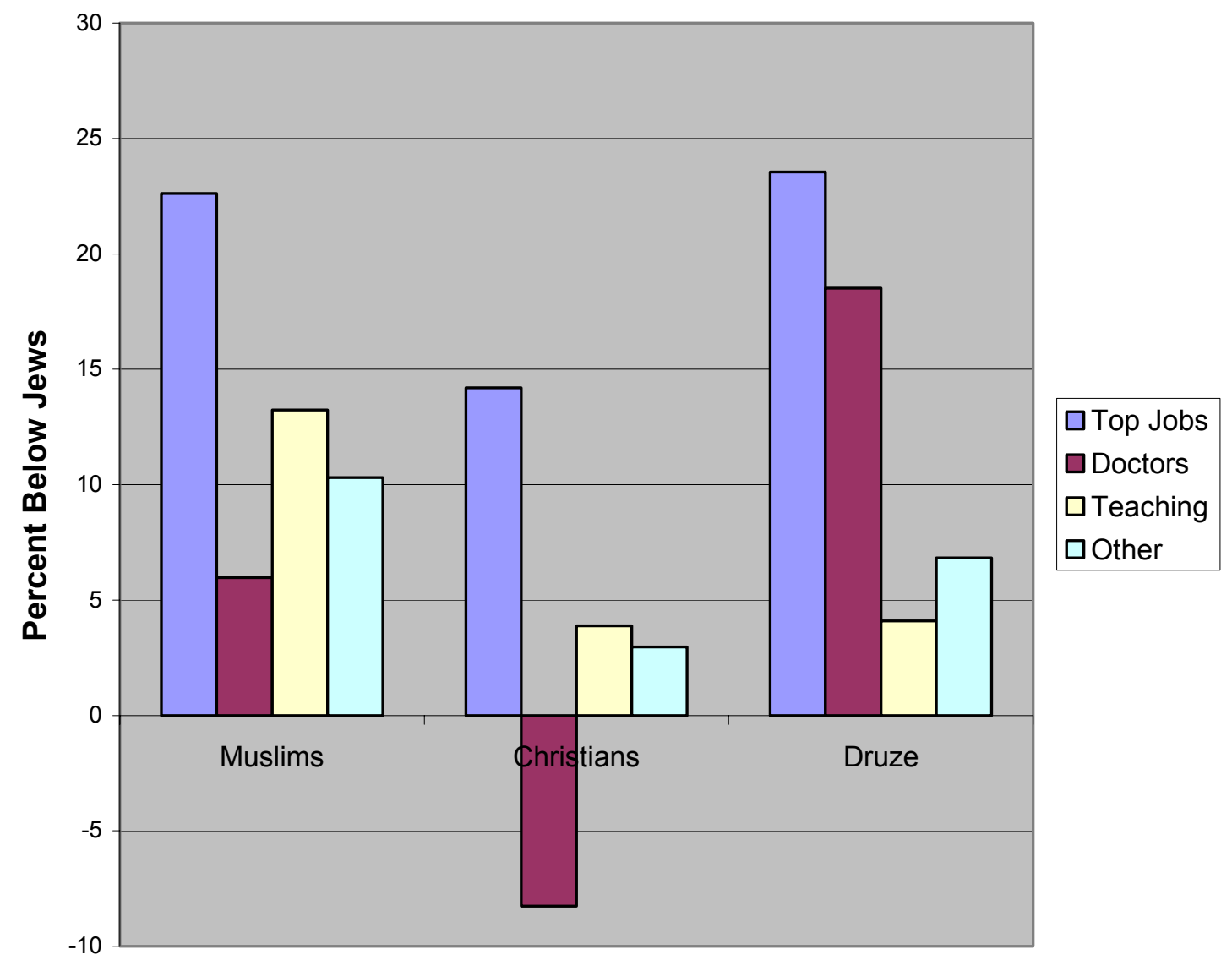


Figure 8 - Unexplained Income Gaps in Top Occupations by Specification

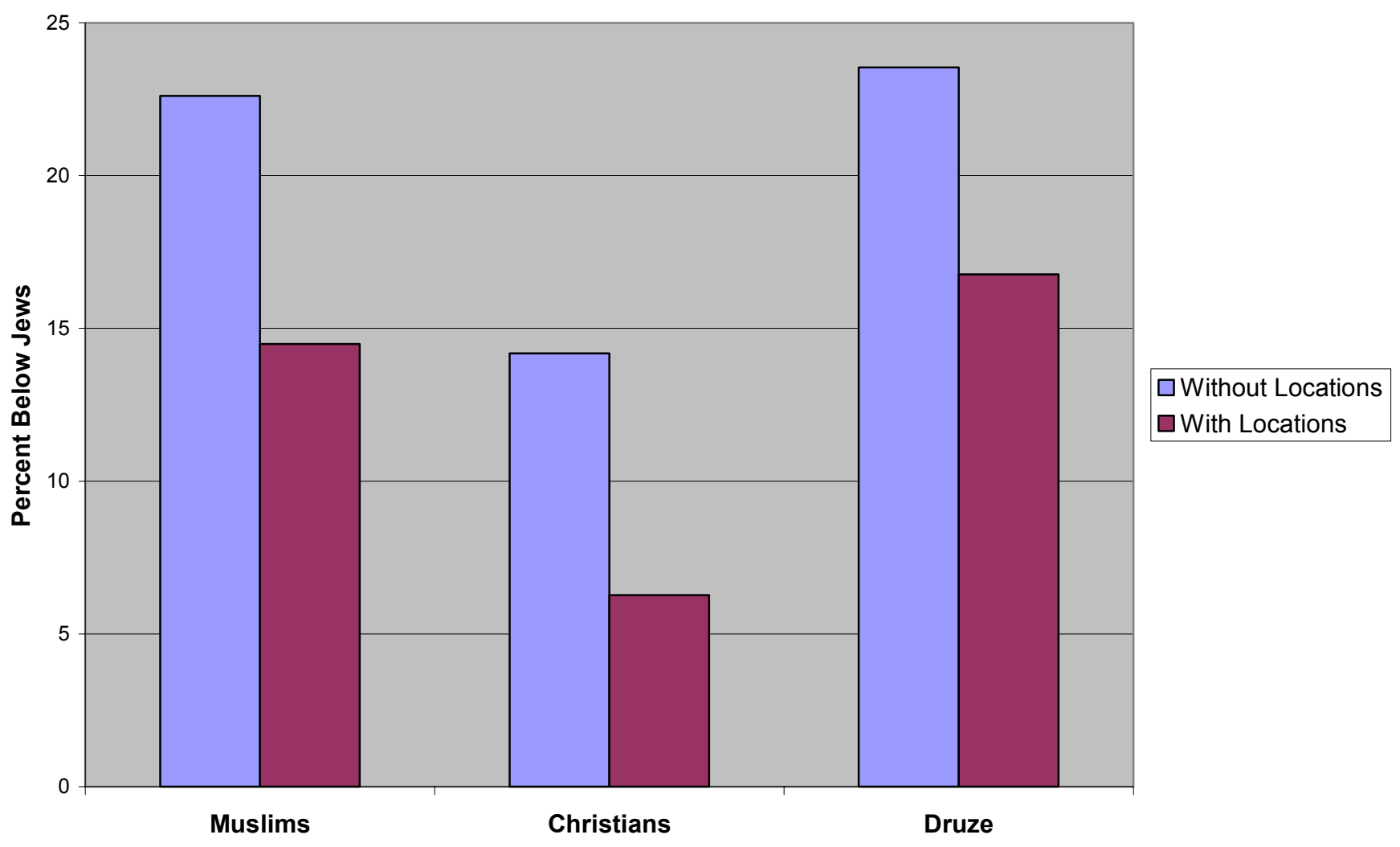

